\title{
A Delphi Study Of Regional Industrial Land-Use\#
}

\author{
OsBin L. ERvin*
}

\section{INTRODUCTION}

The concern of recent years about environmental quality has brought with it a heightened need for new approaches and tools in land-use forecasting. If water and air quality is indeed to be protected and if natural and historic areas are to be preserved, then the urban and regional planner may need to experiment with methods by which emerging land-use patterns can be detected and probable future patterns forecasted. After forecasts of baseline conditions have been made, the planner and policymaker may then intervene to alter the course of events toward the desired objectives. This need for experimentation and innovation in landuse forecasting and analysis seems likely to increase over the next decade at least, because the federal government, the states, and substate regions are clearly moving in the direction of increased control of land use. This is evidenced in national legislation such as the Coastal Zone Management Act and in recent state legislation such as that in Florida and Colorado. ${ }^{1}$

This paper reports on an application of the Delphi method ${ }^{2}$ to regional industrial land-use forecasting. It should be emphasized from the outset that the work documented should be considered no more than an "abbreviated" Delphi approach, for the study was continued through only two rounds and there was no effort to arrive at a stabilized consensus of opinion. Both the methodological and substantive findings of the research are thought to be important and, therefore, both are discussed in the Results section of the paper. Also, because methodology is a major concern of the paper, the way in which the Delphi approach was applied is described fully.

\section{THE FRAMEWORK-REGIONAL LAND-USE SIMULATION}

The research was conducted within the framework of a regional landuse simulation model. ${ }^{3}$ The purpose of the model was to predict future land-use patterns within the 16-county (6500 square mile) East Tennessee Development District (ETDD) (Figure 1).

The simulation model distributes new industrial activity in three stages. In the first stage, regional industrial growth is predicted and new

*Assistant Professor of Political Science, Southern Illinois University-Carbondale.

\# This Research was supported in part by the National Science Foundation RANN Program under

NSF Interagency Agreement No. AAA-R-4-79 with the Oak Ridge National Laboratory. 


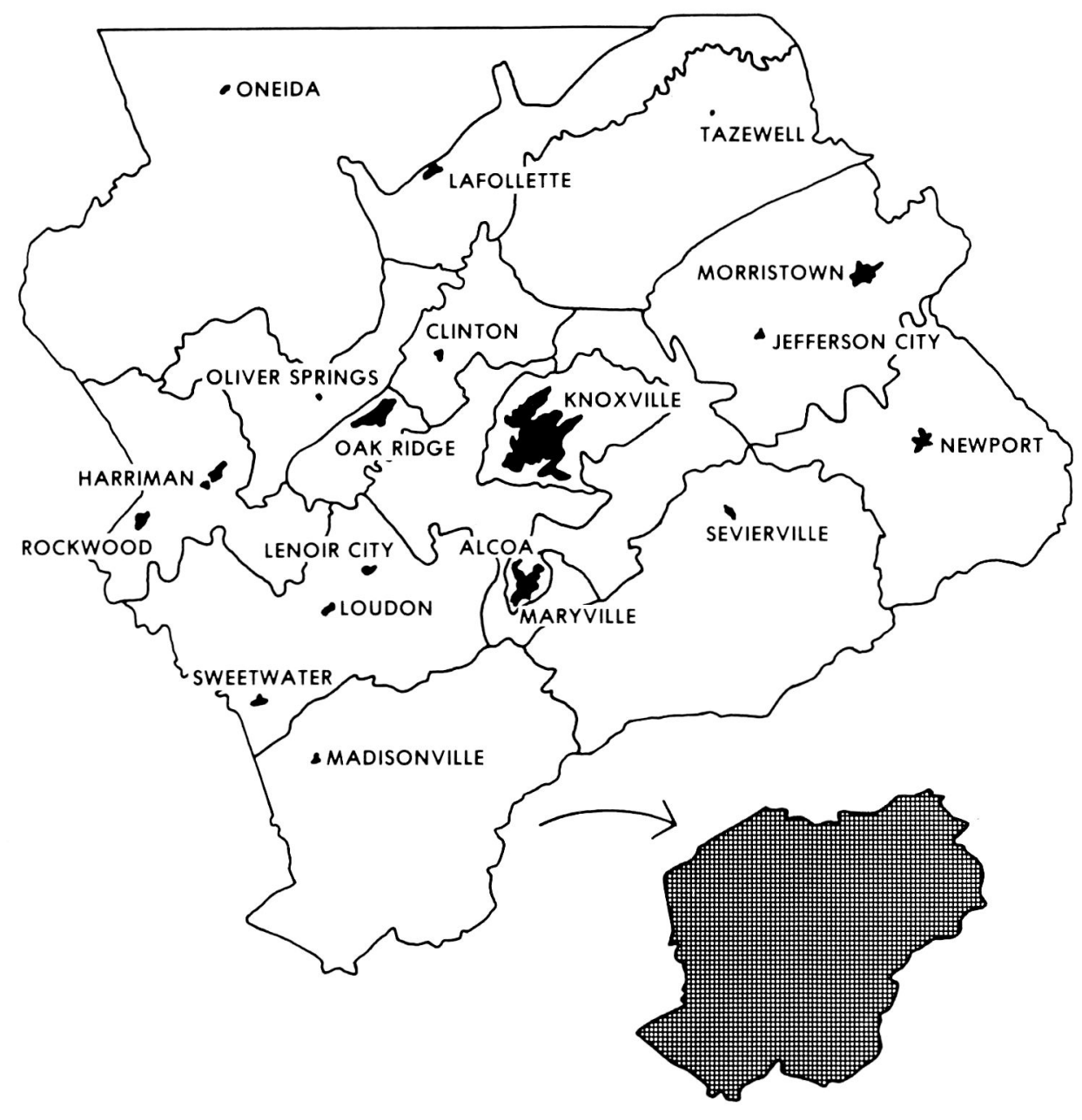

Figure 1: Subregions and cells in the Model Area

increments of industrial employment are assigned to the 16-county model area (Fig. 1). Second, the increments of employment are then converted to specific [2-digit standard industrial classification (SIC)] industrial activities and allocated to homogeneous subregions within the 16-county area. In the final stage, the model makes allocations from the subregional level to "cells," each with an area of 170 acres. (Subregions are shown and cells illustrated in Figure 1.) $)^{4}$

The distribution of specific industrial activities is implemented through land-use attractiveness scores. These scores are calculated for each subregion during the second allocation stage and for each 170-acre cell during the third stage. The scores represent the attractiveness of the subregion or cell for each of the industrial categories being considered. Each 
attractiveness score is a linear function of a set of Industrial Location Factors. $^{5}$

Those subregions or cells with higher attractiveness scores for a particular industrial activity are assigned more of that activity than the subregions or cells with lower scores. This is accomplished through a rank ordering of subregions and cells on each category of industrial activity. Thus, in allocating industrial activity, each subregion and cell is measured in terms of a set of factors (or indices), with each factor weighted according to its importance in the location processes of the various categories of manufacturing activity. Factor measurements for each subregion and cell were obtained through the use of available data and through field surveys for some factors.

An empirical question faced early in the research was: Within the 16-county area, what is the industry-specific importance of the various plant location factors. Regression analysis is the usual way of dealing with this question in simulation modeling. However, after having given serious thought to regression analysis, we decided to adopt a judgmental approach - the Delphi method; it was decided to form a panel of area manufacturers in each major industry and to elicit their opinions and estimates about industrial land-use in the 16-county area. The estimates and opinions would focus on the importance of various industrial location factors and on the future spatial, or geographic, distribution of manufacturing industries.

Both direct and indirect benefits from the use of the Delphi method were anticipated. First, the study would provide data of direct use in developing factor weights for the simulation model, and it seemed likely that the data would be more reflective of contemporary and future conditions in the model area than that which could be derived from other sources. Secondly, it was felt that the interaction with persons in the study area would give land-use researchers and the resulting simulation model a "real world" orientation that might otherwise be lacking.

\section{PROCESSES AND FACTORS IN INDUSTRIAL LOCATION}

A major assumption of this study is that industrial location decisionmaking is a multilevel process. The idea of multilevel location decisions is discussed in a monograph by Malinowski and Kinnard [19]. These researchers argue that there are at least three levels of decisions and that a unique set of factors come into play at each level. The three levels, they argue, are the selection of a region, the selection of one or a few communities within the region, and the selection of a specific plant site.

Thompson [30], in a study conducted for the Small Business Administration, also viewed location decisions as essentially a three-level process. Thompson described the three levels in terms of the choice of 
general area, the choice of community, and choice of site. Because Thompson's study appears to have been designed and documented to meet the actual needs of manufacturing plants (clients of the Small Business Administration), it constitutes a rather strong argument for the reality of such a process in plant location decision making.

In this study, a three-level decision making process is assumed, with the levels being region, subregion (or community), and cell (or plant site). It is further assumed that companies have already chosen the region (the ETDD) and are deciding among specific subregions and cells.

With this intraregional process in mind, sets of subregional and sitespecific location factors were posited. The plant location literature [4, $12,26,30]$ and preliminary discussions with manufacturers, public officials, and industrial development leaders in East Tennessee ${ }^{6}$ suggested that these factors account for the basic patterns of intraregional plant distributions. The subregional factors are:
A. Public service and administration
B. Financial incentives by local government
C. Proximity to similar industry
D. Availability of land with industrial potential
E. Labor availability and skills
F. Local market potential
G. Degree of labor union activity
H. Proximity to raw materials
I. Proximity to support services and supplies
J. Transportation linkages to suppliers and/or markets outside the 16-county region

The site-specific factors are:

K. Neighborhood or community attractiveness and amenities

L. Site preparation costs

M. Transportation accessibility

N. Proximity to suitable labor force

O. Compatibility with existing land uses

P. Utilities

Q. Market price of land

R. Industrial park space

It is clear that no firm line can be drawn between subregional and sitespecific location factors. Some of the subregional factors are no doubt of importance in the final step of site selections. Similarly some of the sitespecific factors may play a locational role well before actual site selections. However, for the most part, the subregional factors are of greater importance before actual site selections, and the site-specific factors are of greater importance in the final step of the plant location process. 


\section{THE DELPHI SURVEY OF MANUFACTURERS}

In an application of the Delphi method to public investment decisions in regional development, Gunther and Vallery [13] introduced the idea of "informed local opinion" (as opposed to the notion of "expert opinion"). These researchers felt that lay members of regional economic development committees could, because of pertinent background and demonstrated interest, contribute valuable forecasts of economic growth potential and problems in their respective regions. This somewhat relaxed conceptualization of the Delphi approach was the one used in this application.

It was felt that manufacturing executives in the ETDD industries were informed and knowledgeable about the locational needs and problems of their respective industries vis-a-vis the characteristics of the ETDDthat a background of training and experience in the particular industry and day-to-day participation in affairs of the local community and region suggested the expertise appropriate to the objective of forecasting regional industrial land-use patterns. Therefore, an attempt was made to form Delphi panels in the various industries represented in the region.

\section{Panel Formation}

A panel of industrial executives was formed in 15 of the 20 (SIC) manufacturing industries (Table 1). Five industries were omitted from the study because of difficulties in finding enough persons well-suited for participation on the panels. The panels were composed mainly of company presidents and plant managers, but other management executives, such as chiefs of marketing and chiefs of purchasing, were included on some of the panels. The panels ranged in size from five to seventeen,

TABLE 1: The Delphi Panels

\begin{tabular}{clc}
\hline SIC group & \multicolumn{1}{c}{ Industry } & $\begin{array}{c}\text { Number of } \\
\text { panelists }\end{array}$ \\
\hline 20 & Food & 17 \\
22 & Textile & 14 \\
23 & Apparel & 16 \\
24 & Lumber and wood (except furniture) & 17 \\
25 & Furniture and fixtures & 17 \\
26 & Paper and pulp & 5 \\
27 & Printing and Publishing & 14 \\
28 & Chemicals & 14 \\
30 & Rubber and plastics & 11 \\
32 & Stone, clay, and glass & 14 \\
33 & Primary metals & 14 \\
34 & Fabricated metals & 14 \\
35 & Machinery (except electrical) & 11 \\
36 & Electrical machinery & 9 \\
38 & Instruments & 16 \\
\hline
\end{tabular}


with a total of 194 manufacturers participating through both rounds of the study.

Two major criteria were used in selecting panelists. First, the person selected had to be an executive in the particular type of manufacturing industry for which the panel was being established. Second, the individual had to be a resident of the 16-county ETDD region. Thus, each panelist could be considered knowledgeable about the matter of industrial location in the ETDD in that he was an executive in the industry and an inhabitant of the region under study. Emphasis was placed on selecting executives in plants that had been located in the region for several years. ${ }^{7}$

After original panels of 10 to 20 persons were formed, each panelist was contacted and asked to participate. In some industries suitable alternates were available and were assigned to panels in which original panelists declined to participate. The survey materials were administered by mail.

\section{Survey Instruments}

Each panelist was asked to rank both subregional and site-specific factors according to their locational importance to his industry. ${ }^{8}$ Instructions for sub-regional and site-specific factors respectively were:

Assume that a manufacturing company of your general type (see attachment) has decided to locate a plant somewhere in the central part of the Eastern Tennessee region (see map) and is now comparing subregions, areas, or counties within the region. With this in mind, how do you rank the importance of the plant location factors below? Place the factor which you think is most important above the number 1 on the scale and the factor which you think is least important above the number 19, and then put the other factors somewhere between these two-according to how important you think they are.

Now assume that a subregion, area, or county has been selected and that a specific site or piece of land must be chosen. With this in mind, how do you rank the importance of the location factors below? Place the factor you think is most important above the number 1 and the one you think is least important above the number 15, and then put the other factors somewhere between these two-according to how important you think they are.

As indicated in the instructions above, panelists ranked the 10 subregional factors on a 19 point scale and the 8 site-specific factors on a 15 point scale.

In the spatial or geographic part of the study, panelists were given a gridded, topographic map of the 16-county region and asked to select the five cells which they believed to be the most attractive to companies in 
their particular industry. The region consisted of all or part of 129 cells, with each cell being $7^{\prime} 30^{\prime \prime}$ latitude by $7^{\prime} 30^{\prime \prime}$ longitude. Figure 4 depicts the relationship of cells to the region. Thus each panelist was asked to choose five growth areas from among a possible 129. And, on an accompanying sheet, panelists were asked to give three reasons for each cell selection.

\section{Feedback Data and Methods}

Panel responses to each factor were summarized and described in a highly graphic way using computer programs especially designed for the feedback task (Fig. 2 is an example of the output). The scale that the panelist used in his first-round response (a 19 point scale for subregional and a 15 point for cell) was presented, and the first-round distribution of panelists, the median, quartiles, and estimate of the individual panelist (indicated by asterisks) were plotted along the scale for each factor. The rank-order of each factor, with reference to its set, was indicated, and, in addition, the factors in each set were listed in the order of their importance. It was felt that this graphic presentation would help each participant in grasping tendencies in his panel's first-round estimates and in understanding the relationship between his own responses and panel tendencies. Each panelist was supplied with a brief explanation of the statistics and the method of presentation.

A summary of the first-round spatial forecasts of each panel was compiled by means of computer programs and a Calcomp Plotter (Fig. 3 is an example). The number of panelists selecting a particular cell was shown by plotting that number within the cell boundaries, and the most frequently given reasons were shown by a smaller coded entry. ${ }^{9}$ These summary (feedback) data were provided to the panelists by means of a second gridded, topographic map of the 16-county area. Clarity and convenience in mailing were the major reasons for the transferal of summary data from the computer output to topographic maps.

GROUP RANK $=1$ TRANSPORTATION LINKS TO SUPPLIES/MARKETS OUTSIDE REGION

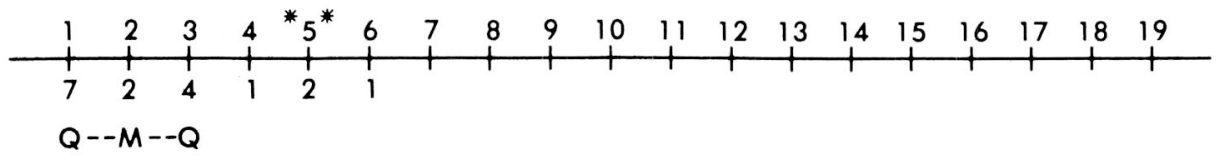

MEDIAN SCORE $=2.0 \quad$ INTERQUARTILE RANGE $=1.0$ TO 3.0

GROUP RANK $=2$ LABOR AVAILABILITY AND SKILLS

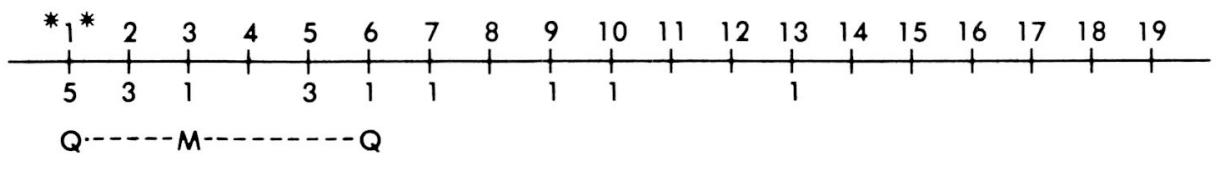

MEDIAN SCORE $=3.0 \quad$ INTERQUARTILE RANGE $=1.0$ TO 6.0

Figure 2: Computer-based feedback of first-round factor rankings, an example 


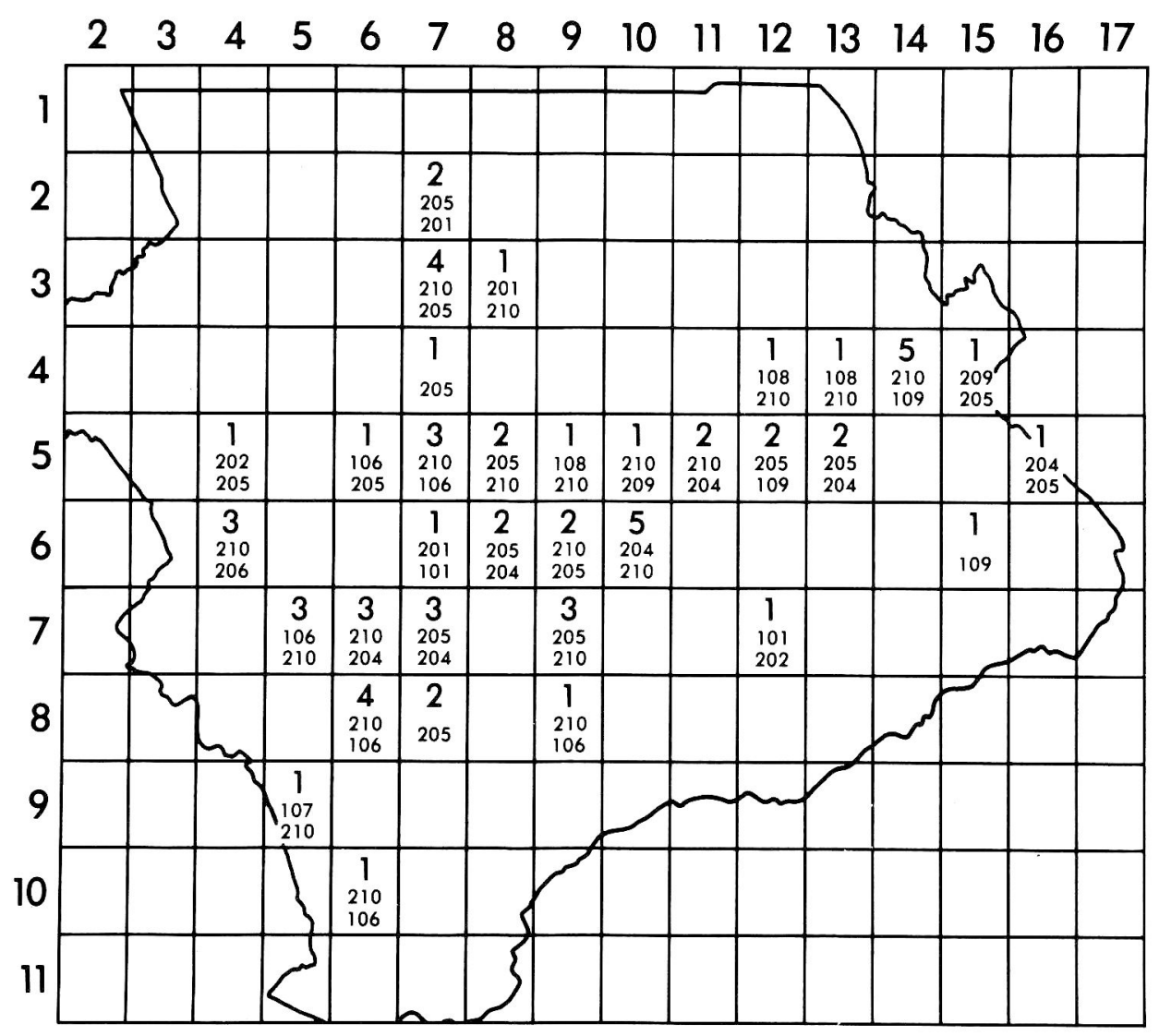

Figure 3: Computer-based feedback on first-round spatial forecasts, SIC 34

After these feedback materials were developed, the panelists were sent the materials, again supplied with ranking sheets and topographic maps, and asked to use the feedback data in ranking the factors and making spatial forecasts a second time. Thus, each panelist was given a chance to apply the beliefs and knowledge of fellow "experts" in a second round of estimates. Second-round responses were summarized in the same way as were first-round responses.

\section{RESULTS}

There are two sets of results of the Delphi study: (1) The substantive findings of the industry-specific rank order of location factors and spatial estimates of future growth areas, and (2) methodological problems, issues 
and reconceptualizations of importance to future application of the Delphi method to land-use matters.

\section{Factor Rank orders and Spatial Forecasts}

Table 2 shows the rank-order of subregional and site-specific factors. Each rank-order of factors is based on the medians of scores assigned by the Delphi panelists.

In terms of factor weights for the land-use simulation model, the rankorder of factors in each set were used in the determination of weights for each industry. In the first stage of the weighting process, subregional factors were given weights ranging from 10 to 1 and site-specific factors given weights ranging from 8 to 1 , in accordance with the position of the factors in their respective rank-orders for the industry in question. For example, in the location of textile companies "labor availability and skills" was assigned a weight of 10 and "local market potential" a weight of 1 . As the weighting process continued however, these weights were modified to take into account additional information from the Delphi study and from other sources.

A major assumption underlying the Delphi study was that the relative importance of the various factors in each of the two sets would vary from one industry to another, and, therefore, that they should be weighted differently in our land-use model. The findings of the Delphi study confirm this assumption.

Judging from the estimates of the panels, some of the location factors are important to some industries and of little importance to others. The subregional factor regarding labor union activity is an illustrative example. The apparel, furniture, and electrical machinery industries appear to consider the union variable highly important. On the other hand, the union variable is of little importance to printing and publishing and several other industries. Similarly, at the site-specific level, community attractiveness is very important to the instruments industry, while it appears to be of little consequence to most other industries.

The findings of the relative importance of the various factors to each industry were also summarized in terms of the appropriate scale (19 point for subregion factors and 15 point for site-specific factors). As in the labor union example (Fig. 4), the SIC number was plotted above the scale number closest to that industry's median for the particular factors.

This display of the data enables one to see inter-industry differences that are camouflaged in the rank-orders of Table 2. For example, the labor union factor is ranked the same (second) by both the apparel and furniture industries. However, Fig. 4 shows that the median score of the apparel panel (SIC 23) was 3, compared to 6 for the furniture panel (SIC 25). While the labor union factor is apparently very important to both industries, it appears to be somewhat more important to the apparel industry than to the furniture industry. 
TABLE 2: The rank order of subregional and site-specific plant location factors

\begin{tabular}{|c|c|c|c|c|c|c|c|c|c|c|c|c|c|c|c|c|}
\hline & & & & & & & & & & & & & & & & \\
\hline & & 20 & 22 & 23 & 24 & 25 & 26 & 27 & 28 & 30 & 32 & 33 & 34 & 35 & 36 & 38 \\
\hline & Public Services and Administration & 3 & 3 & 7 & 8 & 7 & 5 & 4 & 5 & 8 & 8 & 6 & 8 & 4 & 7 & $\overline{4}$ \\
\hline & $\begin{array}{l}\text { Favorability of Local Government } \\
\text { in Financial Incentives }\end{array}$ & 8 & 5 & 3 & 7 & 8 & 8 & 8 & 6 & 5 & 9 & 8 & 7 & 6 & 3 & 5 \\
\hline & $\begin{array}{l}\text { Availability of Land with Industrial } \\
\text { Potential }\end{array}$ & 6 & 6 & 5 & 5 & 6 & 6 & 7 & 3 & 3 & 3 & 1 & 3 & 3 & 5 & 6 \\
\hline & Labor Availability and Skills & 1 & 1 & 1 & 1 & 1 & 1 & 2 & 1 & 2 & 2 & 2 & 2 & 1 & 1 & 1 \\
\hline 柋 & $\begin{array}{l}\text { Transportation Linkages to } \\
\text { Suppliers/Markets }\end{array}$ & 2 & 2 & 4 & 3 & 4 & 3 & 6 & 2 & 1 & 4 & 3 & 1 & 2 & 4 & 2 \\
\hline 空 & $\begin{array}{l}\text { Proximity to Support Services } \\
\text { and Supplies }\end{array}$ & 7 & 4 & 6 & 4 & 5 & 4 & 3 & 4 & 4 & 6 & 7 & 4 & 5 & 6 & 3 \\
\hline & Degree of Labor Union Activity & 9 & 8 & 2 & 6 & 2 & 7 & 9 & 7 & 6 & 7 & 4 & 6 & 7 & 2 & 10 \\
\hline & Local Market Potential & 5 & 10 & 10 & 9 & 10 & 9 & 1 & 9 & 7 & 5 & 9 & 5 & 10 & 10 & 7 \\
\hline & Proximity to Similar Industry & 10 & 9 & 9 & 10 & 9 & 10 & 10 & 10 & 10 & 10 & 10 & 10 & 9 & 8 & 8 \\
\hline & Proximity to Raw Materials & 4 & 7 & 8 & 2 & 3 & 2 & 5 & 8 & 9 & 1 & 5 & 9 & 8 & 9 & 9 \\
\hline & Industrial Park Space & 8 & 8 & 8 & 8 & 5 & 8 & 7 & 7 & 4 & 8 & 8 & 8 & 7 & 5 & 8 \\
\hline & Compatibility with Existing Land Uses & 6 & 7 & 7 & 6 & 8 & 5 & 8 & 6 & 7 & 6 & 4 & 6 & 6 & 8 & 6 \\
\hline 胥 & $\begin{array}{l}\text { Neighborhood or Community } \\
\text { Attractiveness and Amenities }\end{array}$ & 4 & 5 & 6 & 7 & 7 & 6 & 6 & 8 & 8 & 7 & 7 & 7 & 8 & 7 & 1 \\
\hline 星 & Utilities & 3 & 1 & 2 & 3 & 2 & 1 & 1 & 1 & 1 & 3 & 1 & 2 & 2 & 2 & 3 \\
\hline$\overbrace{\infty}^{\infty}$ & Transportation Accessibility & 1 & 3 & 3 & 2 & 4 & 3 & 3 & 3 & 3 & 2 & 3 & 1 & 1 & 3 & 2 \\
\hline 贸 & Proximity to Suitable Labor Force & 2 & 2 & 1 & 1 & 1 & 2 & 2 & 4 & 2 & 4 & 5 & 3 & 3 & 1 & 4 \\
\hline E & Market Price of Land & 5 & 4 & 4 & 4 & 3 & 7 & 4 & 2 & 5 & 1 & 6 & 4 & 5 & 4 & 5 \\
\hline & Site Preparation Costs & 7 & 6 & 5 & 5 & 6 & 4 & 5 & 5 & 6 & 5 & 2 & 5 & 4 & 6 & \\
\hline
\end{tabular}


Figure 4: Summary of panel medians on the labor union factor, an example

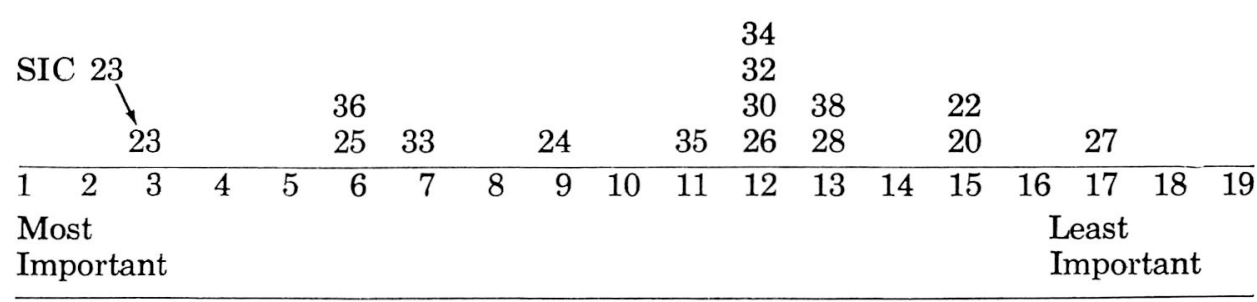

Figure 5 shows the frequency with which panelists chose the various cells in the spatial component of the study. The estimate for the 15 panels have been aggregated to form a composite summary; therefore, the data in Fig. 5 do not give an indication of the estimates of specific industries. The number in a particular cell simply indicates the number of panelists believing the cell is one of the five most likely to attract manufacturing companies during the 10 year (1975-1985) period. Generalized subregion boundaries have been superimposed on the cells to give an indication of the overall industrial attractiveness of each subregion.

In Table 3, the cell $\left(7-1 / 2^{\prime}\right)$ and subregion most frequently selected by each panel (modal cell and subregion) are shown. The data in this table should be studied within the spatial framework of Fig. 5. The table recaptures some of the industry-specific spatial information lost in the overall summary.

As in the case of factor rankings, more specific and detailed information was made available for use in the land-use modeling process. In addition to the composite summary of Fig. 5 and the tabular information in

TABLE 3: Most frequently selected cells and subregions of each panel

\begin{tabular}{lcc}
\hline & \multicolumn{2}{c}{ Selection } \\
\cline { 2 - 3 } Panel & Subregion(s) & Cell \\
\hline SIC 20 (Food) & 1 & 6,9 \\
SIC 22 (Textiles) & 16 & 7,3 \\
SIC 23 (Apparel) & 16 & 6,4 \\
SIC 24 (Lumber and wood) & 8 & 3,7 \\
SIC 25 (Furniture) & 10 & 4,14 \\
SIC 26 (Paper and pulp) & 11 & 6,15 \\
SIC 27 (Printing and publishing) & 1 & 6,9 \\
SIC 28 (Chemicals) & 10 & 4,14 \\
SIC 30 (Rubber and plastics) & 10 & 4,14 \\
SIC 32 (Stone, clay and glass) & 10 & 4,14 \\
SIC 33 (Primary metals) & 10 & 4,14 \\
SIC 34 (Fabricated metals) & 10 & 4,14 \\
SIC 35 (Machinery) & $2,4,10$ & $6,7: 6,8,14$ \\
SIC 36 (Electrical machinery) & 12 & 7,12 \\
SIC 38 (Instruments) & 4,5 & 5,7 \\
\hline
\end{tabular}




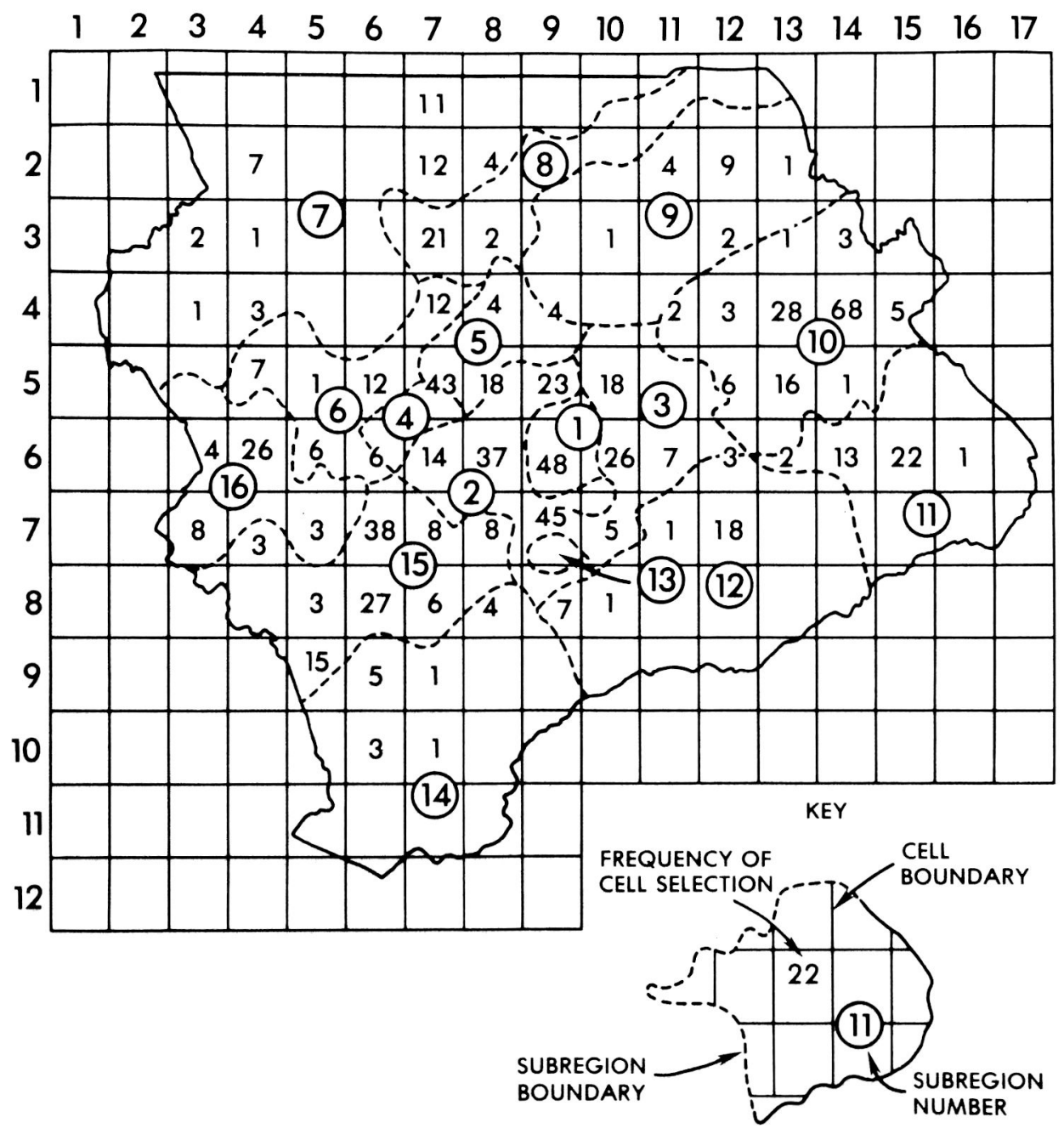

Figure 5: Summary of spatial forecasts

Table 3, the complete spatial forecasts and associated reasons for each panel were provided.

The spatial forecasts and the rank order of subregional factors are generally congruent with and supportive of one another. For example, the electrical machinery panel ranked labor availability and skills, labor union activity, and local financial incentives one, two, and three, respectively; and in the spatial part of the study they indicated that the Sevierville area (cell 7,12 ) of subregion 12 would (over the next 10 years) be the most attractive to companies in their industry. Indeed, interview data confirm that labor factors and financial incentives are highly favorable in subregion 12 and are likely to remain favorable in the immediate future. 


\section{Evaluation of Methodology}

In applying the Delphi method to land-use analysis and forecasting, it was clear from the beginning that at least two apparent incongruities would have to be considered. First, Delphi is usually viewed as a method for long-range technological forecasting; yet, in applying the method to industrial land use, we would be seeking opinion on contemporary relationships and short-range estimates of the future. The second incongruity concerned the spatial nature of land-use analysis. The land-use group needed spatial information, yet the Delphi method had, at that time, been used almost exclusively for tabular, non-spatial estimates. Our results suggest that both incongruities are more illusory than real.

It is true that the Delphi approach has most frequently been used in attempts at long-range forecasting of technological and socioeconomic change. However, there is no reason why the method need always be restricted to judgments about the distant future. Informed opinion and estimates can constitute a valuable source of data about contemporary and little-understood relationships. In our study of industrial land use, panel estimates were pertinent to the present and the near future-the next 10 years. Thus, emphasis was placed on contemporary and shortrange relationships.

The use of a Delphi approach in discovering contemporary relationships and eliciting short-range forecasts holds a great deal of promise for regional and local planning and administration. For example, the method may be well suited to the process of formulating regional or community goals. The major point is that if one will view the Delphi method as a way of eliciting informed judgments and estimates about relationshipshistorical, contemporary, or future - then the range of possible applications becomes considerably wider.

The second problem, adapting Delphi to the spatial dimension, poses more serious but not insurmountable problems. The most serious matter is the development of statistical measures descriptive of frequency distributions across a spatial grid and of spatial convergence and divergence between Delphi rounds. There is an abundance of statistics describing frequencies and frequency change on a number scale; however, available statistical measures applicable to geographic data are inadequate for the description and analysis required in a Delphi study. The absence of appropriate statistics forces the Delphi researcher to rely on imprecise descriptive statements of spatial data. In our use of the method in forecasting industrial location patterns, it was necessary to describe and discuss interround change in terms of the number of times a particular areal cell was selected and in terms of nodes and nodal shifting-terminology too vague and imprecise for a real world of forecasting and planning.

The considerable body of literature in the general area of spatial statistics on "geostatics" constitutes a solid framework for the development of 
statistics specifically tailored for the application of Delphi to spatial analysis and forecasting. ${ }^{10}$ Further research and experimentation holds promise for the development of statistics that will make the Delphi method as applicable to spatial problems as to matters amenable to conventional numeric treatment.

In addition to the discussion of short-range and spatial Delphi studies, three other methodological matters deserve special attention: (1) abbreviated Delphi studies, (2) informed local opinion, and (3) the role of computer technology.

In many cases it may be feasible and desirable to iterate the Delphi questionnaire until opinion stabilizes-through four, five, or more rounds. This is the conventional, well-tested approach, and it has considerable merit. However, reliable and useful data can be acquired through a twoor three-round process. In a short two-round Delphi study, the crucial ingredients of feedback and anonymity are still present. When resources (technology, personnel, time) are in short supply, the land-use researcher or planner may yet be able to elicit informed opinion and estimates through an abbreviated Delphi approach. Such an approach may be particularly applicable in small planning jurisdictions.

Another idea in need for further research and refinement is that of informed local opinion. We should no longer imagine that Delphi participation is restricted to well-established experts in particular fields; average citizens may be well-enough informed about land-use matters in their respective communities to contribute useful, high-quality estimates.

The knowledge displayed by the majority of panelists was one of the most encouraging parts of the survey. While the panelists were not experts on industrial land-use processes, they displayed considerable knowledge about the problems and needs of their respective industries and about the physical, political, and economic characteristics of East Tennessee. In random personal interviews, some panelists were able to name and elaborate on industrial development leaders and programs among the communities of the region. Further, some panelists could go into remarkable detail about the degree to which industry needs, with respect to markets, labor, etc., were satisfied among local communities.

In this study, a computerized system was used for both numerical (non-spatial) and spatial data, for routine statistical and accounting tasks (means, item rank order, etc.), for fully prepared feedback materials in the form of the graphical frequency distributions and spatial displays shown in the previous section, and for final summaries. The techniques of computer-based feedback, both spatial and nonspatial, need to be further refined and tested. One should experiment with various kinds of computer graphics and spatial displays in an effort to determine comparative effectiveness in communicating information and in holding the attention of panelists. In addition, it may be feasible to involve panelists in a direct man-machine on-line system [23] - a system in which panelists 
interact with a computerized data base, with one another, and with a study coordinator by means of remote computer consoles. The on-line system would enable the coordinator to summarize responses and provide feedback instantaneously, considerably decreasing the amount of time necessary for particular study. It is possible that such a methodology will play an important role in future Delphi studies.

\section{CONCLUSION}

The abbreviated Delphi study reported here has yielded information of value in weighting the industrial location factors used in the land-use simulation model. Beyond this direct use of systematically collected and analyzed data, the study was important in providing a mechanism for interaction with the manufacturing executives of the region. This interaction produced information and insights important in dealing with many of the problems encountered in the modeling process. Because of the use of "informed local opinion" the simulation model is doubtless more reflective of the actual land-use conversion processes of the region that would have been the case without a Delphi study.

The substantive (industrial location) results of the study are also pertinent to the problems of land-use, environmental, and industrial development planners and administrators in the East Tennessee region and in similar regions. The factor rankings and spatial forecasts suggest a spatial pattern and mix of future industrial land uses that can serve as a baseline for community and regional policymakers.

This Delphi study was designed as an adjunct to a computer simulation model, and it was directed toward only industrial land use. However, the Delphi method can be used as an independent research or planning tool, and it appears to be just as applicable to commercial and residential land uses as to industrial. Some of the concepts discussed in this study, if further studied and refined, may widen the range of issues and conditions for which Delphi is an appropriate research tool. Among these concepts are: informed local opinion, spatial Delphi analysis, the abbreviated Delphi study, Delphi studies of contemporary relationships, computer-prepared feedback, and on-line analysis.

If these concepts are indeed studied and refined in future research, the Delphi method can become an important tool in regional land-use research and planning. Beyond serving as a research tool, one hopes that the methodology will facilitate citizen participation in problems of land use and environmental management.

\section{FOOTNOTES}

1 The work coming out of the Council of State Governments summarizes and discusses state and national legislation in land-use planning and suggests the need for new approaches and techniques in information processing, forecasting, and planning. See in particular ref- erences [22], [29], and [30]. The monograph by Keyes [16] is a helpful discussion of the ways in which environmental impacts of various land-uses may be estimated.

2The reader who wants an introduction to the theory, application, and evolvement of the 
I)elphi Method should see references [3], [5], [7], [14], [15], and [18]. Also, articles by Fowles [11] and Lazarsfeld [17] discuss Delphi within the broad framework of forecasting methodology and policy science needs. In recent years the Delphi method has come under increasing attack by its detractors-see references [24], [25], and [28]. Exploratory research in application of Delphi to land-use forecasting is described by this author in an earlier paper [10].

:The land-use simulation model is described in a rsearch proposal [21] and in papers by Craven [6], Meyers [20], and Voelker [31].

4 For a discussion of the method by which subregions were delineated, see Durfee [8], and for a description of the way in which data were fitted to the spatial hierarchy (cell-subsegion-region), also see a paper by Durfee [9].

"The relationship is shown in the following equation:

$$
\operatorname{LUS}_{\ell}=\stackrel{\mathrm{L}}{\Sigma_{=}=1} \mathrm{w}_{\mathrm{i}, \ell} \mathbf{I}_{\mathrm{i}, \ell},
$$

where

LUS $_{\ell}=$ attractiveness score for land-use category,

$\mathrm{L}=$ number of factors (indices),

$w_{i}, l=$ weight for the ith index (factor) and the $\ell$ th land-use category,

$I_{1, \ell}=i t h$ index for the $\ell t h$ land-use category.
For a more complete discussion, see reference [21].

"The major contribution of ETDD developers, realtors, public officials, and manufacturers came through their participation in a two-day land-use workshop at Oak Ridge, Tennessee. The workshop was coordinated by the author and sponsored by the Regional Environmental Systems Analysis Program at the Oak Ridge National Laboratory. The participants completed questionnaires about industrial location factors and engaged in discussions with the author and other members of the workshop staff.

iThe Directory of Tennessee Industries [27], was the major source of data for panel formation. Local and regional industrial directories were used as a supplement to the state directory.

sIn the interest of brevity, factor definitions have not been included in this paper. However, definitions of about 40-50 words each were included in the materials sent to panelists. Also, each panelist was asked to base his estimates on trends and conditions that he might foresee developing over the next ten years. The same time frame was used in the spatial part of the study.

?For example, Code 210 refers to the favorability of transportation linkages and facilities.

1"The article by Bachi [1] and the book by Berry and Marble [2] seem particularly important in this regard.

\section{REFERENCES}

1. R. Bachi, "Standard Distance Measures and Related Methods for Spatial Analysis," Regional Science Association Papers, 10 (1963).

2. B. J. L. Berry and D. F. Marble, Spatial Analysis: A Reader in Statistical Geography, Prentice Hall, Englewood Cliffs, N. J., 1968

3. W. L. Brockhaus and J. F. Mickelson, "An Analysis of Prior Delphi Applications and Some Observations on its Future Applicability," Technological Forecasting and Social Change, 10 (number 1, 1977).

A. R. E. Carrier and W. R. Schriver, Plant Location Analysis: An Investigation of Plant Locations in Tennessee, Bureau of Business and Economic Research, Memphis State University, Memphis, Tennesee, 1969.

5. B. Marley-Clark, "The Delphi Method and Urbanization," Long Range Planning, 7 (December, 1974).

6. C. W. Craven, et. al., Reflections on Regional Environmental Systems Analysis, ORNL/RUS-26, Oak Ridge National Laboratory, Oak Ridge, Tenn., 1977.

7. N. C. Dalkey, Studies in the Quality of Life, D. C. Heath, Lexington, Mass. 1972.

8. R. C. Durfee, The Use of Factor and Cluster Analysis in Regional Modeling, ORNL/TM-3720, Oak Ridge National Laboratory, Oak Ridge, Tenn., 1972.

9. R. C. Durfee, ORMIS-Oak Ridge Regional Modeling Information System,
ORNL/NSF/EP-73, Oak Ridge National Laboratory, Oak Ridge, Tenn., 1974.

10. O. L. Ervin, "The Delphi Method: Some Applications to Local Planning," The Tennessee Planner, 32 (1974).

11. J. Fowles, "An Overview of Social Forecasting Procedures," Journal of the American Institute of Planners, 42 (July, 1976).

12. M. L. Greenhut, Plant Location in Theory and Practice, University of North Carolina Press, Chapel Hill, N. C., 1955.

13. W. D. Gunther and J. F. Vallery, Jr., "The Delphi Method as Applied to Public Investment Decisions," The Review of Regional Studies, 1 (Winter, 1971).

14. O. Helmer, Social Technology, Basic Books, New York, 1966.

15. O. Helmer, and N. Resker, "On the Epistomology of the Inexact Sciences," Management Science, 6 (October, 1959).

16. D. L. Keyes, Land Development and the Natural Environment, The Urban Institute, Washington, D. C., 1976.

17. P. F. Lazarsfeld, "The Policy Science Movement (An Outsiders View)," Policy Science, 6 (September, 1975).

18. H. A. Linston and M. Turoff, eds., The Delphi Method: Techniques and Applications, Addison-Wesby, Readings, Mass., 1975.

19. Z. S. Malinowski and W. M. Kinnard, Jr., Personal Factors Influencing Small Manufacturing Plant Locations, University of Connecticut, Storrs, 1961. 
20. C. R. Meyers, Jr., "New Tools for Regional Planning," Journal of the American Institute of Architects, 56 (October, 1971).

21. ORNL-NSF Regional Environmental Systems Analysis Program, A Research Proposal Submitted to the National Science Foundation, RANN, Oak Ridge National Laboratory, Oak Ridge, Tenn., (February, 1972).

22. H. M. Patton, ed., "Special Issue on Land Use," State Government, XLVI (Summer, 1973).

23. H. Sackman and R. L. Citrenbaum, eds., Online Planning, Prentice Hall, Englewood Cliffs, N. J., 1972.

24. H. Sackman, "Summary Evaluation of Delphi," Policy Analysis 1 (Fall, 1974).

25. Harold Sackman, Delphi Critique, D. C. Heath, Lexington, Mass., 1975.

26. D. M. Smith, Industrial Location, Wiley, New York, 1971
27. Staff Division for Industrial Development, The Directory of Tennessee Industries, State of Tennessee, Nashville, Tenn., 1973.

28. A. Stander, and T. Richards, "The Oracle That Failed," Long Range Planning, 8 (October, 1975).

29. The Council of State Governments, Organization, Management, and Financing of State Land Use Programs, Lexington, Kentucky, 1974.

30. The Council of State Governments, Land: State Alternatives for Planning, Lexington, Kentucky, 1975.

31. J. H. Thompson, Methods of Plant Site Selection Available to Small Manufacturing Firms, Bureau of Business Research, West Virginia University, 1961.

32. A. H. Voelker, Some Pitfalls of Land-Use Model Building, ORNL/RUS-1, Oak Ridge National Laboratory, Oak Ridge, Tenn., 1975. 